\title{
The Influence of Preoperative Bladder Outlet Obstruction on Continence and Satisfaction in Patients with Stress Urinary Incontinence after Midurethral Sling
}

\author{
Su Jin Kim, Hang Won Choi, Hyuk Jin Cho, Tae-Kon Hwang, Joon Chul Kim \\ Department of Urology, Bucheon St. Mary's Hospital, The Catholic University of Korea School of Medicine, Bucheon, Korea
}

\begin{abstract}
Purpose: We studied the influence of preoperative bladder outlet obstruction (BOO) on postoperative continence rates and patient satisfaction after the midurethral sling procedure.

Methods: A total of 159 women who underwent the midurethral sling procedure were evaluated. Using the Blaivas-Groutz nomogram, we assigned the patients were assigned to Group I ( $\mathrm{n}=37$, no obstruction), Group II ( $\mathrm{n}=89$, mild obstruction), or Group III ( $n=33$, moderate to severe obstruction). Continence rates, patient satisfaction, urinary sensation scale and uroflowmetry were evaluated postoperatively.

Results: There were no significant differences in continence rates, satisfaction, or postoperative maximal flow rate between the 3 groups. Postoperative urgency was improved after surgery in Groups I and II $(\mathrm{P}<0.05)$ but not in Group III.

Conclusions: BOO does not seem to be a risk factor for failure after the midurethral sling procedure. However, BOO may be considered as a potential factor for persistent storage symptoms after the midurethral sling.
\end{abstract}

Keywords: Bladder outlet obstruction; Suburethral sling; Urinary stress incontinence

\section{INTRODUCTION}

Bladder outlet obstruction (BOO) is not usually diagnosed in women with lower urinary tract symptoms (LUTS). Recently, there have been many reports about the prevalence and importance of BOO in women. According to one study on the value of evaluating the voiding phase when performing urodynamic study in woman, about $33 \%$ of patients had disorders in micturition. The causes included disorders affecting the bladder outlet such as dysfunctional voiding, a moderately severe cystocele, primary bladder neck obstruction and external detrusor sphincter dyssynergia [1]. Because there is no standard urodynamic definition of BOO in women, efforts to develop a standard definition have resulted in several proposals of urodynamic criteria for a diagnosis made by pressure flow study [2-4].
Stress urinary incontinence (SUI) is a common problem and it is well known that overactive bladder (OAB) symptoms such as frequency and urgency often coexist with SUI. Consequently, there have been many studies about the influence of $\mathrm{OAB}$ on the outcomes after a midurethral sling procedure in women with SUI $[5,6]$. However, there are no studies on women with both SUI and BOO or on the influence of BOO on the results after the midurethral sling. Because BOO can coexist with SUI, the outcome after the midurethral sling procedure might be affected by underlying $\mathrm{BOO}$ in such patients.

Therefore, we documented the prevalence of $\mathrm{BOO}$ in women with SUI by using the Blaivas-Groutz nomogram [4] and evaluated the influence of BOO on outcomes after the midurethral sling procedure.
Corresponding author: Joon Chul Kim

Department of Urology, Bucheon St. Mary's Hospital, The Catholic University of Korea School of Medicine, 2 Sosa-dong, Wonmi-gu, Bucheon 420-717, Korea Tel: +82-32-340-7071 / Fax: +82-32-340-2124 / E-mail: kjc@catholic.ac.kr Submitted: December 11, 2010 / Accepted after revision: December 23, 2010
This is an Open Access article distributed under the terms of the Creative Commons Attribution Non-Commercial License (http://creativecommons.org/licenses/by-nc/3.0/) which permits unrestricted non-commercial use, distribution, and reproduction in any medium, provided the original work is properly cited. 


\section{MATERIALS AND METHODS}

The medical records of 248 women who underwent a midurethral sling procedure owing to SUI for 2 years were reviewed. Among them, 159 women who were followed for at least 12 months were included in this study. All patients underwent a physical examination with a comprehensive history, urinalysis, a 3-day voiding diary, and evaluation of urgency grade by use of a urinary sensation scale. Patients who had neurological diseases, previous radical pelvic surgeries or pelvic organ prolapses were excluded from this study. According to the International Continence Society recommendations, urodynamic investigations were performed with a 7 Fr dual-lumen urethral catheter and a 9 Fr rectal balloon catheter at a filling rate of $50 \mathrm{~mL} / \mathrm{min}$. Cystometry and the pressure-flow study were performed with the patient in the sitting position. $\mathrm{BOO}$ was defined by using the Blaivas-Groutz nomogram [4] and the patients were assigned to Group I ( $n=37$, no obstruction), Group II ( $n=89$, mild obstruction), or Group III ( $\mathrm{n}=33$, moderate to severe obstruction). The MONARC transobturator sling (American Medical Systems, Minnetonka, MN, USA) was applied in all patients. The postoperative evaluation included an assessment of the outcome, LUTS, the degree of urgency based on a urinary sensation scale, the maximum flow rate (Qmax), and postvoid residual urine volume (PVR). Continence status was defined as cure, improvement or failure. Cure was defined as the absence of any episodes of involuntary urine leakage during stressful activities. Improvement was defined as a more than $50 \%$ reduction in incontinence during stressful activities. Failure was defined as a less than $50 \%$ reduction in incontinence during stressful activities. Satisfaction was assessed using a questionnaire regarding each patient's

Table 1. Continence rate and patient's satisfaction after midurethral sling

\begin{tabular}{lccc}
\hline & $\begin{array}{c}\text { Group I } \\
(\mathrm{n}=37)\end{array}$ & $\begin{array}{c}\text { Group II } \\
(\mathrm{n}=89)\end{array}$ & $\begin{array}{c}\text { Group III } \\
(\mathrm{n}=33)\end{array}$ \\
\hline $\begin{array}{l}\text { Continence } \\
\text { Cure }\end{array}$ & $31(83.8)$ & $76(85.4)$ & $28(84.8)$ \\
Improve & $5(13.5)$ & $10(11.2)$ & $4(12.1)$ \\
Fail & $1(2.7)$ & $3(3.0)$ & $1(3.0)$ \\
Satisfaction & & & \\
Satisfied & $32(89.2)$ & $81(91.0)$ & $29(87.8)$ \\
Same & $4(10.8)$ & $5(5.6)$ & $3(9.1)$ \\
Worse & $1(2.7)$ & $3(3.4)$ & $1(3.0)$ \\
\hline
\end{tabular}

Values are presented as number (\%). feeling about her voiding status ( 5 , very satisfied; 4 , satisfied; 3 , equally satisfied and unsatisfied; 2 , unsatisfied; 1 , very unsatisfied). We judged that patients were satisfied with their voiding status if they gave a score of 4 or 5 . Dissatisfaction was recorded as a score of 1 or 2 .

Statistical analysis was performed by using SPSS ver. 12.0 (SPSS Inc., Chicago, IL, USA). The data were analyzed by using the Kruskall Wallis test among the 3 groups and the Wilcoxonsigned rank test in each group. Significance was set at a value of $\mathrm{P}<0.05$.

\section{RESULTS}

The mean patient age was $55.6 \pm 8.4$ years (range, 39 to 72 years) and the mean follow-up period was $24.3 \pm 9.6$ months (range, 12 to 45 months). BOO was diagnosed in 122 of the 159 patients with SUI (77\%); mild obstruction was observed in 89 (56\%) and moderate to severe obstruction was observed in 33 (21\%). There were no significant differences in the cure rates (Group I, 83.8\%; Group II, 85.4\%; Group III, 84.8\%), and there was no significant difference in patient satisfaction (Group I, 89.2\%; Group II, 91.0\%; Group III, 87.8\%) (Table 1). There were no significant differences between the preoperative and postoperative Qmax value within each group. However, a significantly lower preoperative Qmax was observed in Group III (20.5 \pm 5.7 $\mathrm{mL} / \mathrm{sec})$ than in Group I $(24.5 \pm 5.7 \mathrm{~mL} / \mathrm{sec})$. The postoperative Qmax was also significantly lower in Group III $(24.5 \pm 5.7 \mathrm{~mL} /$ sec) than in Group I (26.8 $\pm 9.1 \mathrm{~mL} / \mathrm{sec})$ (Fig. 1). The preopera-

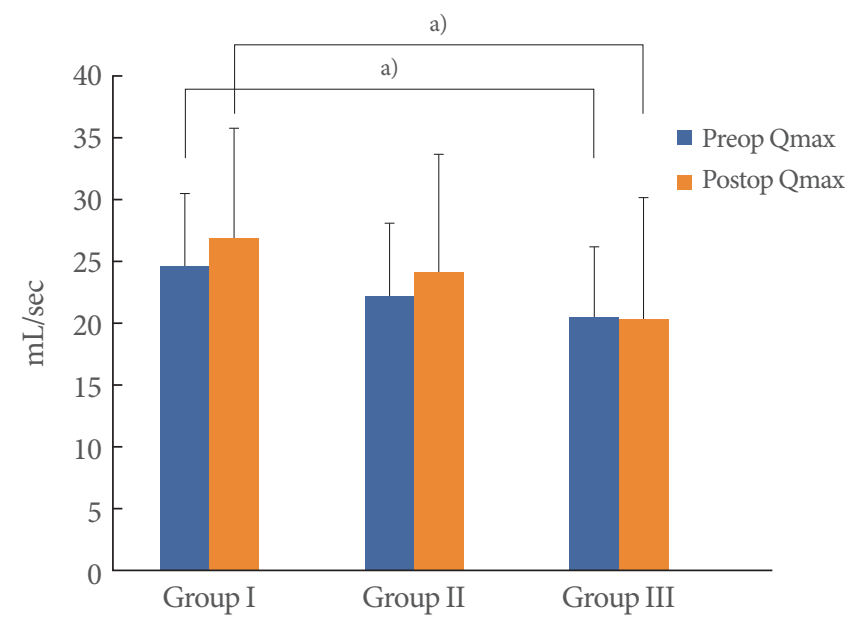

Fig. 1. Changes of preoperative (preop) and postoperative (postop) maximal flow rate (Qmax). ${ }^{\text {a) }} \mathrm{P}<0.05$ compared with Group I. 


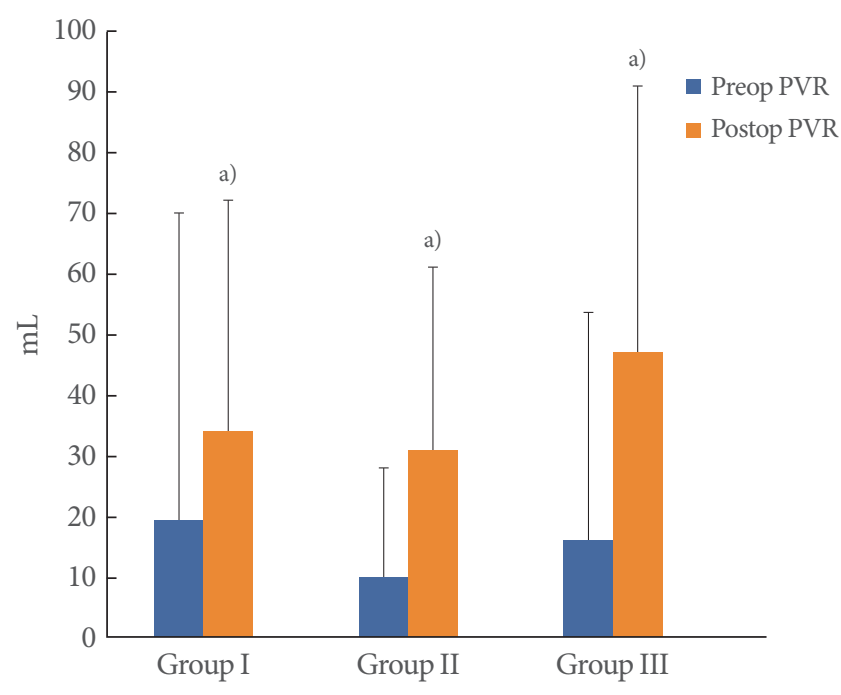

Fig. 2. Changes of preoperative (preop) and postoperative (postop) postvoid residual urine volume (PVR). ${ }^{\text {a) }} \mathrm{P}<0.05$ compared with preop PVR.

tive and postoperative PVR were not significantly different among the 3 groups. However, PVR was significantly increased in each group postoperatively $(\mathrm{P}<0.05)$. The preoperative and postoperative PVR were $19.7 \pm 50.5 \mathrm{~mL}$ and $34.3 \pm 38.0 \mathrm{~mL}$ in Group I, $10.2 \pm 18.3 \mathrm{~mL}$ and $31.1 \pm 30.5 \mathrm{~mL}$ in Group II and $16.4 \pm 37.5 \mathrm{~mL}$ and $47.1 \pm 44.1 \mathrm{~mL}$ in Group III (Fig. 2). The preoperative urgency grade from the urinary sensation scale of Groups I, II and III were 3.1 $\pm 1.5,2.9 \pm 1.5$ and $2.5 \pm 1.7$, respectively and there were no significant differences among the groups. The postoperative urgency grades by urinary sensation scale in Groups I, II, and III were $1.5 \pm 1.0,1.8 \pm 0.9$ and $1.9 \pm 1.1$, respectively, and there were no significant differences among the groups. The postoperative symptom of urgency was significantly improved after the midurethral sling in Groups I and II $(\mathrm{P}<0.05)$. However, there was no improvement in urgency in Group III (Fig. 3). Six women complained of voiding difficulties during the follow-up period. Among them, 3 women belonged to Group I and the rest belonged to Groups II and III.

\section{DISCUSSION}

In these women with SUI, having underlying BOO in these women with SUI showed no influence on the continence rate or patient satisfaction after the midurethral sling procedure. However, urgency was not easily improved postoperatively among patients with higher grades of BOO, so this should be considered a potential factor in the persistence of urgency after

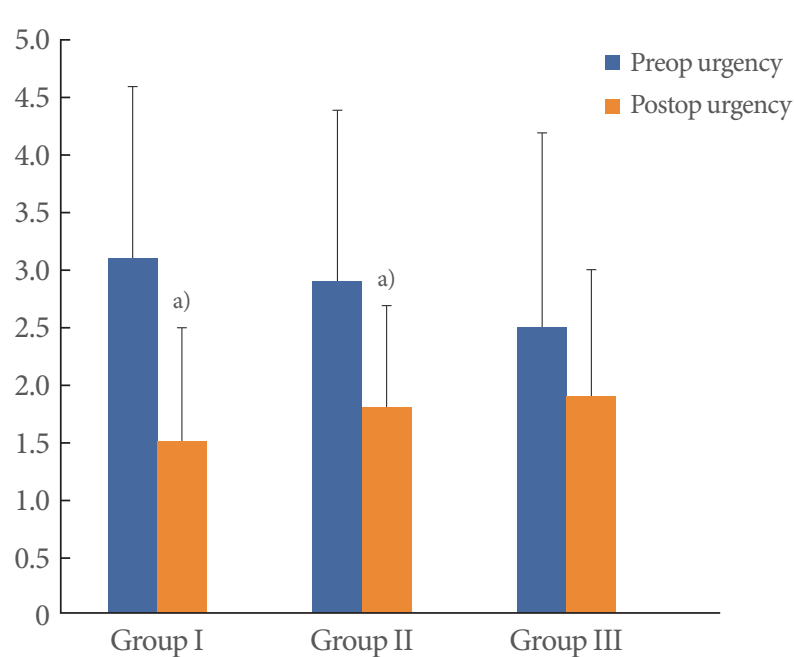

Fig. 3. Changes of preoperative (preop) and postoperative (postop) urgency by urinary sensation scale. ${ }^{\text {a) }} \mathrm{P}<0.05$ compared with preoperative urgency.

this procedure.

Several studies have defined BOO as one of the important causes of LUTS in women as well as men. Because there is no standard definition of BOO for women, the incidence has been reported diversely. In one study, 33\% of the women complaining of LUTS was diagnosed with BOO. The authors recommended a routine evaluation of the voiding phase when performing urodynamic testing [1]. Moreover, BOO was noted in $18.3 \%$ of the women with SUI reported by Bradley and Rovner [7]. In the present study, 76.7\% (122/159) of the patients with SUI were defined as having BOO. This high incidence might have arisen from our diagnostic criteria because some investigators have suggested that the Blaivas-Groutz nomogram overestimates the real incidence in women [8,9]. However, most of our patients were defined as having a mild form of BOO, and only $20.8 \%$ $(33 / 159)$ were rated as having moderate to severe BOO. For this reason, the patients with moderate to severe degree of $\mathrm{BOO}$ were considered to show meaningful degree of BOO, clinically. Preoperatively, the Qmax of women with mild BOO was not significantly lower than that of women with no obstruction. However, women with moderate to severe BOO showed significantly lower Qmax values than did women with mild BOO. Therefore, we consider that this subgroup of patients with a higher degree of BOO had similar characteristics to those of women with BOO defined by other criteria $[2,3,7,8]$ and that this was clinically meaningful compared with patients with mild BOO. 
The continence rate after the midurethral sling procedure is reported as ranging from 83 to $95 \%$ [10-12]. Despite this high cure rate, some patients are not satisfied with the results and show no effect or recurrence after the procedure. There have been many studies identifying the risk factors. Women with SUI usually show concomitant OAB symptoms such as frequency, urgency, and nocturia. There have been some attempts to define the association between detrusor overactivity and adverse outcomes after the midurethral sling procedure [13-15]. However, little research has been done on the influence of $\mathrm{BOO}$ on the outcome after the midurethral sling procedure in patients with SUI. The continence rate in this series was similar to previous reports regardless of the degree of $\mathrm{BOO}$ [10-12]. In addition, the patient satisfaction rating was similar regardless of the severity of BOO. Despite the preoperative low Qmax in patients with underlying BOO, the Qmax after midurethral sling application was not significantly reduced in these patients, as with patients with no obstruction. We already excluded any patients with iatrogenic, anatomic or neurogenic causes of BOO. Therefore, BOO caused by functional impairment was considered not to correlate with the adverse results after midurethral sling. Consequently, we suggest that functional $\mathrm{BOO}$ is not a risk factor for failure after this procedure. Although postoperative PVR was significantly increased in each group, the objective range of PVR was within the normal range. Also PVR was not significantly different before and after the midurethral sling among each group. This finding also supports our proposal that the underlying $\mathrm{BOO}$ may not be a risk factor for failure.

$\mathrm{BOO}$ has been regarded as one cause of detrusor overactivity and $\mathrm{OAB}$ in men with benign prostatic hyperplasia. Several theories about the underlying mechanism have been proposed, such as denervation sensitivity, altered afferent pathways involving cholinergic and purinergic neurotransmission, and a urothelial mechanism [16-18]. In contrast, studies on the influence of BOO on LUTS and its pathophysiology in women are lacking. However, some investigators have recognized that iatrogenic BOO following SUI surgery might lead to refractory $\mathrm{OAB}$ symptoms in women and that this could result in persistent symptoms that are not relieved after urethrolysis [19-21]. From these results, we suppose that BOO may induce changes in bladder function and in $\mathrm{OAB}$ symptoms in women as well as in men. In the present study, we compared the degree of urgency to define the characteristics and differences before and after the midurethral sling procedure according to the severity of pre- operative $\mathrm{BOO}$ because urgency is the representative symptom of OAB.

Preoperative urgency was not significantly different in any of the 3 groups. According to Metin et al. [22], more urgency symptoms are observed among patients with SUI and BOO than in patients without $\mathrm{BOO}$. These different results might be arisen from the definition of BOO and urgency between the studies. Metin et al. [22] used the Abrams-Griffith, LinPURR and Schaefer Contractility nomograms to define BOO. Urgency was assessed from a patient history, and they did not use a specific urgency scale. Because these nomograms were designed to be applied to the evaluation of men with BOO, they are inappropriate criteria for women. Moreover, urgency might have been under- or overestimated compared with our results because Metin et al. [22] did not use a specific urgency scale.

After the midurethral sling procedure, patients with no obstruction or mild obstruction showed significant improvements in urgency in this series. However, the degree of urgency was not reduced in the patients with moderate to severe obstruction. Therefore, underlying BOO might be a cause of the persistent or refractory urgency and $\mathrm{OAB}$ symptoms after SUI surgery. Despite the improvements in urgency symptoms and SUI after midurethral sling, some patients show persistent urgency symptoms [5]. Typically, the factors leading to persistent or refractory urgency after this procedure have been considered to relate to functional problems of the bladder such as detrusor overactivity, and there has been little concern about the urethral cause in women. Persistent urgency is an important factor that reduces the quality of life after the midurethral sling procedure [5]. Therefore, it is necessary to suspect the existence of underlying $\mathrm{BOO}$ in such patients.

In this study, we hypothesized that $\mathrm{BOO}$ might be one cause of persistent urgency after the midurethral sling procedure. The pathophysiology of $\mathrm{OAB}$ induced by $\mathrm{BOO}$ in women might be similar to that in men, but further evaluation is necessary to define the mechanism. Moreover, a consensus about the pathophysiology of $\mathrm{BOO}$ in women is required.

Underlying BOO might not have adverse effects on the continence rate and patient satisfaction after the midurethral sling procedure. However, underlying BOO in women with SUI can influence on their LUTS and postoperative persistent urgency. Therefore, it is necessary to bear in mind that BOO may be a potential cause of causing persistent urgency after anti-incontinence surgery in women. 


\section{CONFLICT OF INTEREST}

No potential conflict of interest relevant to this article was reported.

\section{REFERENCES}

1. Carlson KV, Fiske J, Nitti VW. Value of routine evaluation of the voiding phase when performing urodynamic testing in women with lower urinary tract symptoms. J Urol 2000;164:1614-8.

2. Defreitas GA, Zimmern PE, Lemack GE, Shariat SF. Refining diagnosis of anatomic female bladder outlet obstruction: comparison of pressure-flow study parameters in clinically obstructed women with those of normal controls. Urology 2004;64:675-9.

3. Nitti VW, Tu LM, Gitlin J. Diagnosing bladder outlet obstruction in women. J Urol 1999;161:1535-40.

4. Blaivas JG, Groutz A. Bladder outlet obstruction nomogram for women with lower urinary tract symptomatology. Neurourol Urodyn 2000;19:553-64.

5. Tahseen S, Reid P. Effect of transobturator tape on overactive bladder symptoms and urge urinary incontinence in women with mixed urinary incontinence. Obstet Gynecol 2009;113:617-23.

6. Botros SM, Miller JJ, Goldberg RP, Gandhi S, Akl M, Beaumont JL, et al. Detrusor overactivity and urge urinary incontinence following trans obturator versus midurethral slings. Neurourol Urodyn 2007;26:42-5.

7. Bradley CS, Rovner ES. Urodynamically defined stress urinary incontinence and bladder outlet obstruction coexist in women. J Urol 2004;171(2 Pt 1):757-60.

8. Akikwala TV, Fleischman N, Nitti VW. Comparison of diagnostic criteria for female bladder outlet obstruction. J Urol 2006;176:2093-7.

9. Massolt ET, Groen J, Vierhout ME. Application of the BlaivasGroutz bladder outlet obstruction nomogram in women with urinary incontinence. Neurourol Urodyn 2005;24:237-42.

10. Meschia M, Bertozzi R, Pifarotti P, Baccichet R, Bernasconi F, Guercio E, et al. Peri-operative morbidity and early results of a randomised trial comparing TVT and TVT-O. Int Urogynecol J Pelvic Floor Dysfunct 2007;18:1257-61.

11. Rinne K, Laurikainen E, Kivela A, Aukee P, Takala T, Valpas A, et al. A randomized trial comparing TVT with TVT-O: 12-month results. Int Urogynecol J Pelvic Floor Dysfunct 2008;19:1049-54.

12. Barry C, Lim YN, Muller R, Hitchins S, Corstiaans A, Foote A, et al. A multi-centre, randomised clinical control trial comparing the retropubic (RP) approach versus the transobturator approach (TO) for tension-free, suburethral sling treatment of urodynamic stress incontinence: the TORP study. Int Urogynecol J Pelvic Floor Dysfunct 2008;19:171-8.

13. Duckett JR, Basu M. The predictive value of preoperative pressureflow studies in the resolution of detrusor overactivity and overactive bladder after tension-free vaginal tape insertion. BJU Int 2007; 99:1439-42.

14. Kuo HC. Effect of detrusor function on the therapeutic outcome of a suburethral sling procedure using a polypropylene sling for stress urinary incontinence in women. Scand J Urol Nephrol 2007;41: 138-43.

15. Lai HH, Simon M, Boone TB. The impact of detrusor overactivity on the management of stress urinary incontinence in women. Curr Urol Rep 2006;7:354-62.

16. Housami F, Abrams P. Persistent detrusor overactivity after transurethral resection of the prostate. Curr Urol Rep 2008;9:284-90.

17. de Groat WC. The urothelium in overactive bladder: passive bystander or active participant? Urology 2004;64(6 Suppl 1):7-11.

18. Kim JC, Yoo JS, Park EY, Hong SH, Seo SI, Hwang TK. Muscarinic and purinergic receptor expression in the urothelium of rats with detrusor overactivity induced by bladder outlet obstruction. BJU Int 2008;101:371-5.

19. Scarpero HM, Dmochowski RR, Nitti VW. Repeat urethrolysis after failed urethrolysis for iatrogenic obstruction. J Urol 2003;169: 1013-6.

20. Starkman JS, Duffy JW 3rd, Wolter CE, Kaufman MR, Scarpero HM, Dmochowski RR. Refractory overactive bladder after urethrolysis for bladder outlet obstruction: management with sacral neuromodulation. Int Urogynecol J Pelvic Floor Dysfunct 2008;19:277-82.

21. Starkman JS, Duffy JW 3rd, Wolter CE, Kaufman MR, Scarpero HM, Dmochowski RR. The evolution of obstruction induced overactive bladder symptoms following urethrolysis for female bladder outlet obstruction. J Urol 2008;179:1018-23.

22. Metin A, Kayigil, Ahmed SI. The rate of urgency symptoms in women with stress urinary incontinence and nomogram based bladder outlet obstruction. Int Urol Nephrol 2000;32:251-3. 